\title{
The detection of lung cancer using massive artificial neural network based on soft tissue technique
}

\author{
Kishore Rajagopalan ${ }^{*}$ (D) and Suresh Babu
}

\begin{abstract}
Background: A proposed computer aided detection (CAD) scheme faces major issues during subtle nodule recognition. However, radiologists have not noticed subtle nodules in beginning stage of lung cancer while a proposed CAD scheme recognizes non subtle nodules using x-ray images.

Method: Such an issue has been resolved by creating MANN (Massive Artificial Neural Network) based soft tissue technique from the lung segmented $x$-ray image. A soft tissue image recognizes nodule candidate for feature extortion and classification. X-ray images are downloaded using Japanese society of radiological technology (JSRT) image set. This image set includes 233 images (140 nodule $x$-ray images and 93 normal x-ray images). A mean size for a nodule is $17.8 \mathrm{~mm}$ and it is validated with computed tomography (CT) image. Thirty percent $(42 / 140)$ abnormal represents subtle nodules and it is split into five stages (tremendously subtle, very subtle, subtle, observable, relatively observable) by radiologists.

Result: A proposed CAD scheme without soft tissue technique attained 66.42\% (93/140) sensitivity and 66.76\% accuracy having 2.5 false positives per image. Utilizing soft tissue technique, many nodules superimposed by ribs as well as clavicles have identified (sensitivity is $72.85 \%(102 / 140)$ and accuracy is $72.96 \%$ at one false positive rate).

Conclusion: In particular, a proposed CAD system determine sensitivity and accuracy in support of subtle nodules (sensitivity is $14 / 42=33.33 \%$ and accuracy is $33.66 \%$ ) is statistically higher than CAD (sensitivity is 13/42 = 30.95\% and accuracy is $30.97 \%$ ) scheme without soft tissue technique. A proposed CAD scheme attained tremendously minimum false positive rate and it is a promising technique in support of cancerous recognition due to improved sensitivity and specificity.
\end{abstract}

Keywords: X-ray, Sensitivity, Lung cancer, Subtle, Accuracy

\section{Background}

\section{General}

Cells (https://www.cancer.net/) were vital units in our lung region, which were having its unique framework. Cancer (https://www.healthline.com) is a syndrome which might appear as an increased abnormal cell uncontrollably. However, it happens across any portion of

\footnotetext{
* Correspondence: kishoreresearchscholar@gmail.com

Department of Electronics and Communication Engineering (ECE), Kamaraj college of engineering and technology (Autonomous), Virudhunagar, India
}

a body [1]. So, it results in the change in genetic behavior [1] which deter the regular flow (cell may fabricate new cells during early stages and it dies while they were growing old). It might have a possibility for producing cancer in the lymphatic system. Doctors partition cancer into categories based on its foundation. The categories were listed as Carcinomas, Sarcomas, Leukemias as well as Lymphomas (https://www.medicalnewstoday.com/articles/323648) [1].

(c) The Author(s). 2020 Open Access This article is licensed under a Creative Commons Attribution 4.0 International License, which permits use, sharing, adaptation, distribution and reproduction in any medium or format, as long as you give appropriate credit to the original author(s) and the source, provide a link to the Creative Commons licence, and indicate if changes were made. The images or other third party material in this article are included in the article's Creative Commons licence, unless indicated otherwise in a credit line to the material. If material is not included in the article's Creative Commons licence and your intended use is not permitted by statutory regulation or exceeds the permitted use, you will need to obtain permission directly from the copyright holder. To view a copy of this licence, visit http://creativecommons.org/licenses/by/4.0/ The Creative Commons Public Domain Dedication waiver (http://creativecommons.org/publicdomain/zero/1.0/) applies to the data made available in this article, unless otherwise stated in a credit line to the data. 
The most significant utility for lung was holding a stream utilizing oxygen within the entire body. However, blood flow was interrupted through these cancer. Lung cancer is a single hazardous syndrome, which might present in small as well as non small cell [2]. It is a prime cause for both genders in many countries. Early detection has high endurance rate. But, it is usually noticed late due to the lack of symptom in its early phases [3].

Lung cancer recognition (moziani.tripod.com) in premature phase has no symptom. However, during this phase, the root cause has not well known. Once doctors discovered root cause has been ignored by the patient, which result in late diagnosis and further treatment. Lung cancer endurance prolongs to fall. Hence, $7.6 \%$ males as well as $11.3 \%$ females are net survival predicted during 2013-2017 [4] and it is indicated in Table 1.

Nodules seen within an x-ray image might not essentially be lung cancer, it reports an abnormality which was specified as pneumonia, tuberculosis or calcified granuloma. So, it was a tedious work for radiologists during the past few decades. Lung nodule widens towards the chest center since natural lobe situated across the lung region needs to be known earlier [5]. However, it is a exigent task of radiologists since ribs and clavicles are being overlapped with it.

$\mathrm{X}$-ray utilize few energy with direction in obtaining imagery rooted in body's interior structure. They are frequently accustomed toward assisting with identifying cracked bone, glance for wound or infection and to find a strange object in soft tissue. These might utilize an iodinebased contrast material or barium to build up the visibility of specific organ, blood vessels, tissues or bone. So, it has been used to identify chest syndromes because they are most cost-effective, routinely available and dose-effective diagnostics. However, X-ray images are suited for the improvement done in the image processing technique which does not need iodine-based contrast material to pick up the visibility of a specific organ. Hence, $30 \%$ nodules in.

$\mathrm{x}$ ray image are missed by radiologists and that, $82-$ 95\% missed nodules are partly obscured by overlying

Table 1 Lung cancer standardised one, five and 10 year net survival (2013-2017)

\begin{tabular}{llll}
\hline Sex & Years after diagnosis & Number of cases & Net surivival (\%) \\
\hline Female & 1 year & $85,270.0$ & 44.5 \\
Male & 1 year & $98,357.0$ & 37.1 \\
Persons & 1 year & $183,627.0$ & 40.6 \\
Female & 5 years & $85,270.0$ & 19.0 \\
Male & 5 years & $98,357.0$ & 13.8 \\
Persons & 5 years & $183,627.0$ & 16.2 \\
Female & 10 years & $134,006.0$ & 11.3 \\
Male & 10 years & $157,189.0$ & 7.6 \\
Persons & 10 years & $291,195.0$ & 9.5 \\
\hline
\end{tabular}

bone such as ribs and clavicles [6, 7]. For solving the issue of detecting nodule which is overlapping with ribs and clavicles, we proposed a novel CAD scheme of MANN based soft tissue technique.

\section{Related works}

J.S. Lin [8] used two level neural classifiers for reducing false positive through computer aided analysis. However, lung cancer was recognized [9]. A co-occurrence matrix using texture measures [10] has been employed in support of malignant nodule recognition.

Most ordinary problems encountered throughout nodule finding was overlapping rib and clavicle with a nodule. Existing computer aided detection scheme known as most efficient tool since it was missing lung nodule due to overlapping rib. When we utilize an overlapped image, it was difficult in detecting a suspicious area. Several imaging techniques have been proposed during recent literature review such as analyzing texture, watershed segmentation [11], Gaussian filters [12], active shape modeling [13] and quasi-Gabo filters [14].

In [15], feature sets hold translation invariant wavelet with co-occurrence mammogram attributes were used in image categorization. Features extracted from multi scale Gaussian filter bank and some specific features that were readily calculated from blob detector scheme to detect nodules [16]. Local curvature using image data was considered when viewed using relief map [17].

Matsumoto et al., proposed computer aided detection scheme using $\mathrm{x}$-ray images at 11 false positive rates, even though the system had $80 \%$ sensitivity. But lung nodule detection accuracy was not improved [18]. Feng Li et al. $[19,20]$ detects small lung cancers in $\mathrm{x}$-ray image for false positive reduction. This would increase their confidence level of radiologist by utilizing dual energy subtraction technique. However, using such technique requires specialized equipments and dual energy images are prone to motion artifact.

To address this problem, dual energy subtraction strategies using radiation exposures [21] were considered for decomposing a radiograph into bone-free and soft tissue free image. So, it had been widely accepted in clinical practice because its clinical value can improve diagnostic efficiency. However, there were problems such as high radiation dose and motion artifacts due to double exposure with different energies. This problem had been addressed by using deep learning [22]. Deep Learning has assumed that there was a nonlinear relationship between dual energy image. If the nonlinear relationship was deduced using deep learning, a dual energy image could be generated from single energy chest radiography without double exposures.

They had utilized chest radiograms in training (lung image database consortium (LIDC-IDRI)) database [22]. Their training data utilized in this study were a single 
energy and dual energy chest radiogram pair. They utilized single energy chest radiogram and dual energy soft tissue free image. Deep learning model is a U-net based model and they added a shortcut connection between convolution layers. To optimize such a learning model, they had utilized the adaptive momentary estimation (ADAM) optimization method.

The virtual dual energy [22] bone free chest radiogram was obtained by subtracting the predicted dual energy soft tissue free chest radiograms from the conventional single energy chest radiogram. Kenji Suzuki developed pixel based device mechanism using medical image processing which avoids error caused by inaccurate feature calculation and segmentation while classifying objects into certain classes [23]. Takeshi Kobayashi, Xin-Wei $\mathrm{Xu}$, Heber MacMahon, Charles E. Metz, Kunio Doi evaluate the consequence on nodule output by utilizing ROC analysis with two diverse techniques involved in computer aided diagnosis scheme [24]. Donghoon Lee, Hwiyoung Kim, Byungwook Choi, Hee-Joung Kim developed a deep learning which reduces double exposure with improvement of diagnostic accuracy [25].

In this work, MANN based soft tissue technique has been expanded with JSRT image set in support of subtle nodule recognition. It will facilitate a proposed computer aided detection scheme without double $\mathrm{x}$-ray exposures.

\section{Methods}

\section{Database of X-ray image}

A 247 image set has been downloaded from the Japanese Society of Radiological Technology (JSRT) (http://db.jsrt. or.jp/eng.php). From that, 140 abnormal and 93 normal images were selected. Detail is made available in Table 2.

Selected images have been subjected to nodule detection with absence in opaque portions. These sizes were $2048 \times 2048$ pixels. All nodules in this database were validated by computed tomography and their location was verified by chest radiologists. A digitized image having 12 bits with a pixel quality of $2048 \times 2048$. A pixel size

Table 2 Allotment of nodules in the JRST database based on nodule size

\begin{tabular}{lllll}
\hline & \multicolumn{2}{l}{ Size $(\mathrm{mm})$ categories } & Total \\
\cline { 2 - 4 } & Small & Medium & Large & \\
\hline Tremendouslysubtle & 2 & 18 & 5 & $25(16.2 \%)$ \\
Very subtle & 3 & 16 & 10 & $29(18.8 \%)$ \\
subtle & 4 & 29 & 17 & $50(32.5 \%)$ \\
Relatively observable & 1 & 20 & 17 & $38(24.7 \%)$ \\
observable & 0 & 5 & 7 & $12(7.8 \%)$ \\
Pathology & & & & \\
$\quad$ Benign & 7 & 34 & 13 & 54 \\
$\quad$ Malignant & 3 & 54 & 43 & 100 \\
\hline
\end{tabular}

was $0.175 \times 0.175 \mathrm{~mm}$. Subtle nodule may be divided into five stages which are tremendously subtle, very subtle, subtle, observable, relatively observable.

A MANN based soft tissue technique has been created for discerning precise opacity from other opacities in chest radiography. So, it is utilized to differentiate subtle nodules. This technique was required when it has acquired equipping image by rib suppression and was evaluated by 233 images. The allotment of nodules in the JRST database was based on its size and précised in Table 2.

Shiraishi et al. [26] have eliminated cases in this study comprising lung nodule in opaque scenarios for $\mathrm{x}$-ray image that match up to the retro-cardiac as well as subdiaphragmatic areas of the lung. However, 7.6\% (76/ 1000) of these scenarios belong to these areas. Opaque scenarios represent $9.1 \%(14 / 154)$ of the JRST dataset.

\section{Existing computer aided detection scheme}

At a University of Chicago Hospital in a Department of Radiology (https://radiology.uchicago.edu/about/earlyyears), $\mathrm{x}$-rays were acquired utilizing a single exposure based dual energy radiography system. Original image dimensions was $1760 \times 1760$. This dimension is reduced to $512 \times 512$ by utilizing sub sampling for a considerable decrease in computation time.

\section{Overview}

First module employs an imaging pipeline [27] which contains lung separation from other arrangements by utilizing $x$-ray with an area being suspected as an abnormality. With this module, the system extracts $65 \times 65$ square areas for considering suspicious point positioned within middle area. Because it employs pixel-based method, every pixel situated in square area were believed as system inputs. The intensity values fall within these inputs were extorted and stored in a database was utilized to train system at second module. The database was alienated into a number of subcategories, and the information offered in these subcategories would be utilized for the training as well as for testing the results. In a second module, neural network was equipped through input categories which are named as statistical feature based inputs and pixel based inputs.

An existing computer aided detection scheme include four major steps which is represented in Fig. 1: A) pre-processing B) Binary image conversion and connected component analysis C) feature extortion D) classification.

It contains two modules which were depicted inside Fig. 2.

Pre-processing When they utilized median filtering technique during preprocessing step, the poor contrast 


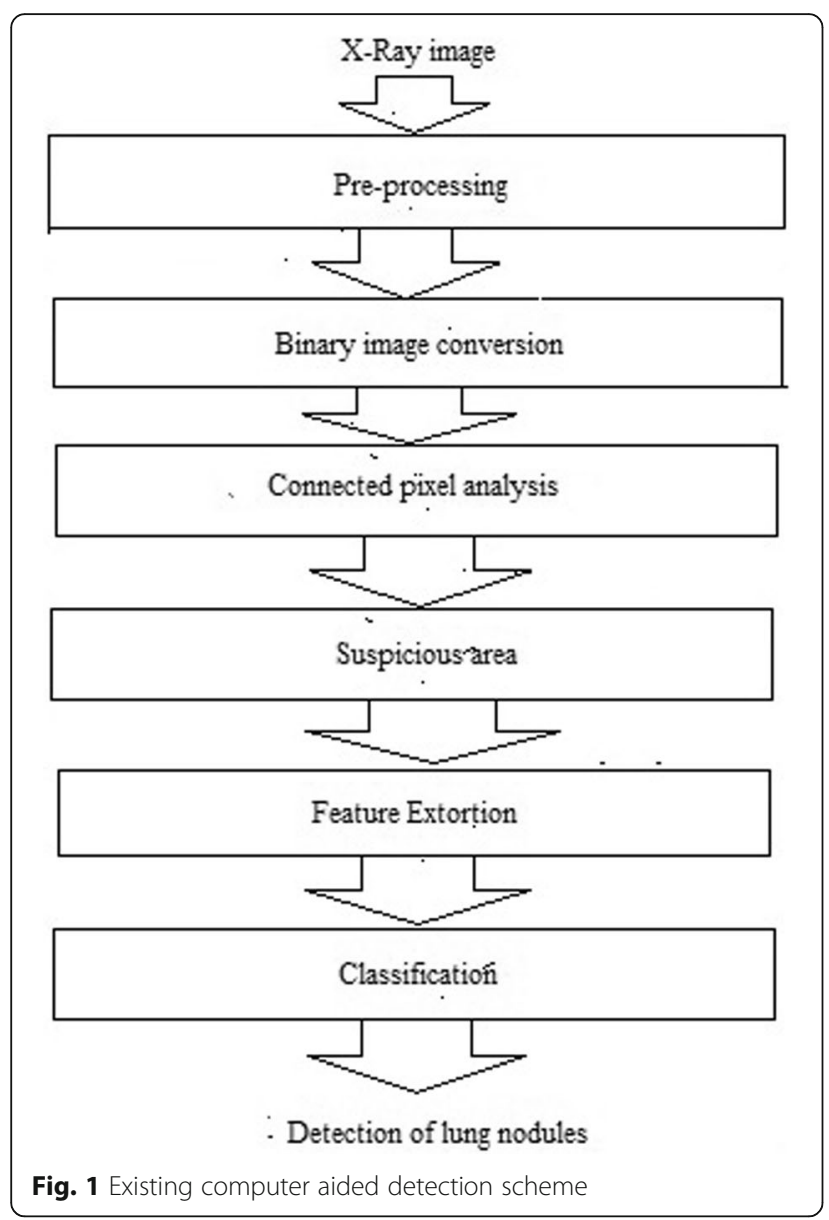

effect had eliminated. A low frequency image was created by substituting pixel value with median pixel value over a square area as $5 \times 5$ pixel centered at pixel location. Sharpening and histogram equalization techniques were utilized in the direction of enhancing image contrast.

Binary image conversion and connected component analysis Binary image conversion [27] has been done to make a computation apt for threshold procedure. By utilizing threshold image, lung masks were prepared through active shape models. However, these masks may be utilized in the connected component analysis during scope identification while user selecting suspicious points [27]. So, lung mask was utilized to group pixel region as an element. i.e., every pixel region having a related element was related to each other.

The criterion for $\mathrm{x}$-ray image enclosure using JSRT image set were: (1) nodule absence bigger than $35 \mathrm{~mm}$, (2) suspicious nodule absence that were not launched by CT examination, and (3) nodule absence with margin that might not be established by a radiologist. The subtlety holded within this image set are clustered into five categories, namely, observable, relatively observable, subtle, very subtle and tremendously subtle. These categories have been described by expert radiologists which takes into account size, contrast, and anatomical position of the lesion.

Feature extortion Fourteen features were extorted from the above method (Binary image conversion and connected component analysis) and listed in Table 3.

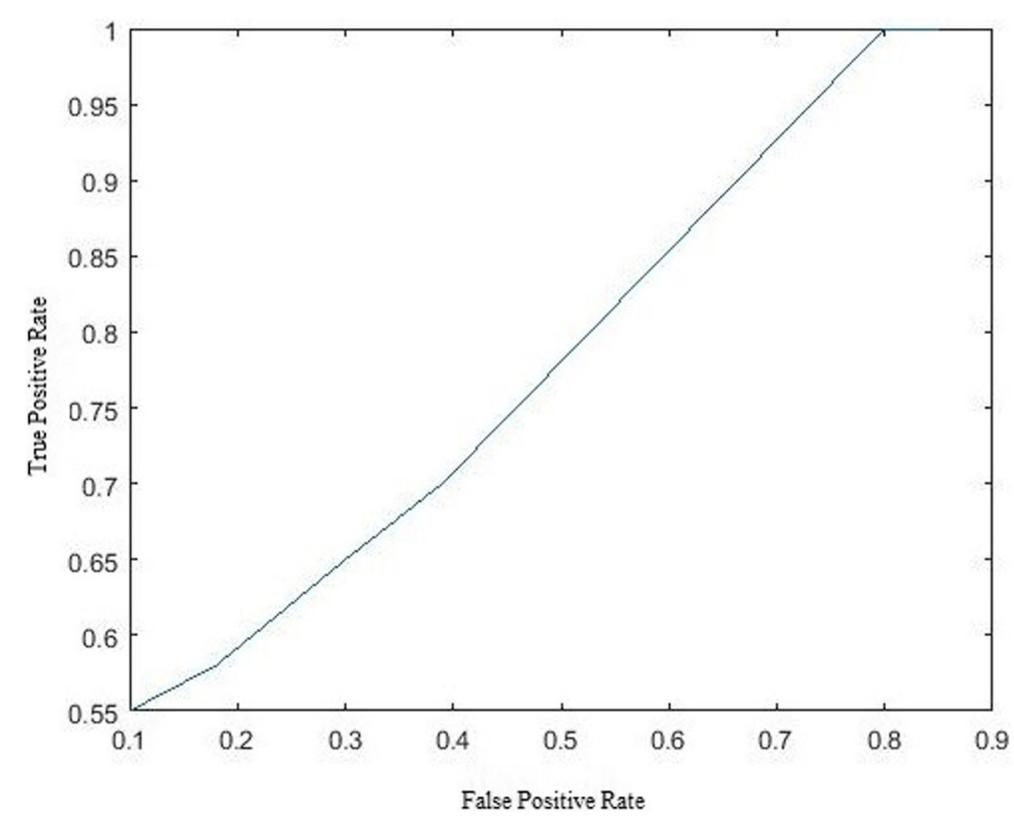

Fig. 2 ROC Curve 
Table 3 Features extorted using existing computer aided detection scheme

\begin{tabular}{ll}
\hline S.No. & Extorted feature \\
\hline 1 & Contrast value \\
2 & Correlation value \\
3 & Energy value \\
4 & Homogeneity value \\
5 & Gray level \\
6 & Mean \\
7 & Standard Deviation \\
8 & Entropy \\
9 & Circularity \\
10 & Uniformity \\
11 & Smoothness of the intensity \\
12 & Skewness of the histogram \\
13 & Area \\
14 & Perimeter \\
\hline
\end{tabular}

The circular index of each connected module $M_{i}$ is defined as

$$
\mathrm{M}_{\mathrm{i}}=4 J I \mathrm{~A}_{\mathrm{i}} / \mathrm{R}_{\mathrm{i}}^{\wedge} 2
$$

Where $A_{\mathrm{i}}$ is the area (nodule) of each image in JSRT image set, $R_{i}$ is the perimeter (nodule) of each image in JSRT image set. It is calculated based on the area and the perimeter. If a connected module exhibits a circular index nearer to 1 , then there is a high probability of nodule consideration. After recognizing a region that illustrates a high probability of being a nodule, this scheme proceeds to the second phase of their algorithm to train the classification.

Classification A neural network having one hidden layer of 1000 neurons and an input layer of 10 neurons to hold the first and second order textures were utilized at the training phase. Based on the utilization of the

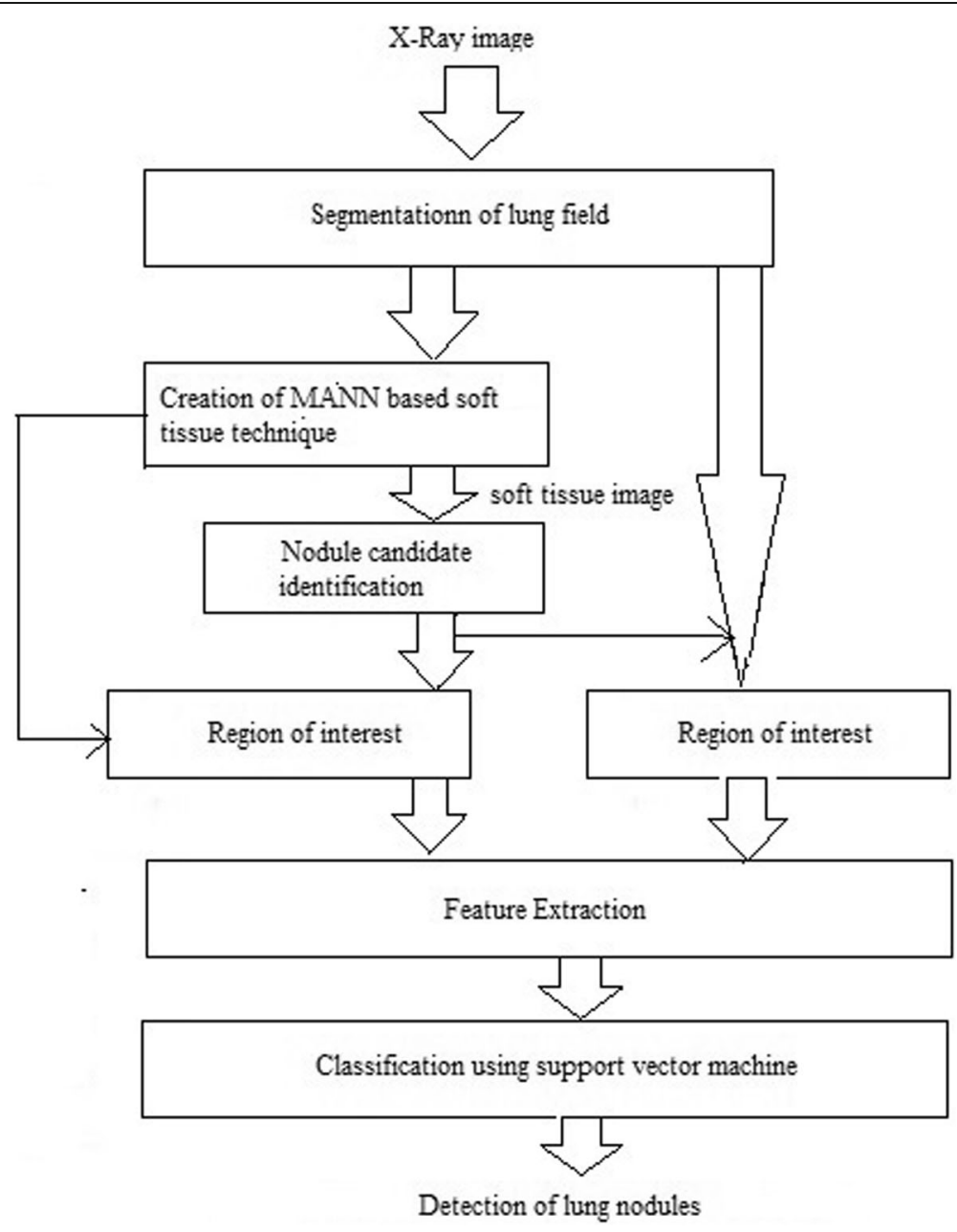

Fig. 3 Proposed computer aided detection scheme 
training phase, subtle nodules were grouped into five categories which are named as observable, relatively observable, subtle, very subtle and tremendously subtle. It is based on size, contrast, and anatomical position of the nodule.

\section{Creation of MANN based soft tissue technique}

In the radiography field, MANN filter $[28,29]$ was involved. However, this was vital to discriminate precise opacity from other opacities. MANN based soft tissue technique was created (described in eq. 9) by utilizing $x$ ray. It was used as rib and clavicle suppressed [30] form. Figure 3 show soft tissue technique creation using $x$-ray. MANN [31], nonlinear filter has equipped. Bone imaging has been acquired by means of dual energy radiography methods and it was utilized as equipping image. Equation (2) represents a mapping of input vector utilizing neural network.

The MANN contain linear-output ANN regression model which is able to handle image data directly.

$$
\mathrm{f}(\mathrm{u}, \mathrm{v})=\mathrm{NN}\left(\mathrm{a}_{\mathrm{u}, \mathrm{v}}\right)
$$

Where $a_{u, v}=\left\{g(u-i, v-j) \mid u-i, v-j \in R_{s}\right\}$ is an input vector to MANN which represent sub region, $f(u, v)$ represent an estimate of a teaching value. Equation (3) represents an actual function of rib suppression between input vectors and training values. $\mathrm{R}_{\mathrm{s}}$ and $\mathrm{R}_{\mathrm{t}}$ denote sub and training region.

$$
\begin{aligned}
& \left\{\mathrm{a}(\mathrm{u}, \mathrm{v}), \mathrm{T}(\mathrm{u}, \mathrm{v}) \mid \mathrm{u}, \mathrm{v} \in \mathrm{R}_{\mathrm{T}}\right\} \\
& \quad=\left\{\left(\mathrm{a}_{1}, \mathrm{~T}_{1}\right)\left(\mathrm{a}_{2}, \mathrm{~T}_{2}\right) \ldots \ldots\left(\mathrm{a}_{\mathrm{N}}, \mathrm{T}_{\mathrm{N}}\right)\right\}
\end{aligned}
$$

Where $\mathrm{T}(\mathrm{u}, \mathrm{v})$ is a training image and $\mathrm{N}$ is pixel number in training region. For a sole MANN, rib holding different frequencies maintains complex suppression due to limited ability. With an intention of conquering this issue, multi resolution decomposition/composition techniques were applied. First lower resolution image $G_{L}(u$, v) acquired from higher resolution image $G_{H}(2 u, 2 v)$ by executing down sampling with average, i.e., four pixels replaced by a mean value of four pixels represented by an eq. (4)

$$
G_{L}(u, v)=\frac{(1 / 4) \sum G_{H}(2 u-i, 2 v-j)}{u, v \in R_{22}}
$$

Where $R_{22}$ represent $2 \times 2$ region. The lower resolution area replaced four regions having the same value through up sampling, were represented in an eq. (5) as follows:

$$
\begin{aligned}
& G_{L}^{U}(u, v)=G_{L}(u / 2, v / 2) \\
& \mathrm{S}=\boldsymbol{G}_{\boldsymbol{L}}^{U}(\boldsymbol{u}, \boldsymbol{v})
\end{aligned}
$$

Then, enlarged lower resolution region is subtracted from higher resolution region shown in eq. (6) and (7)

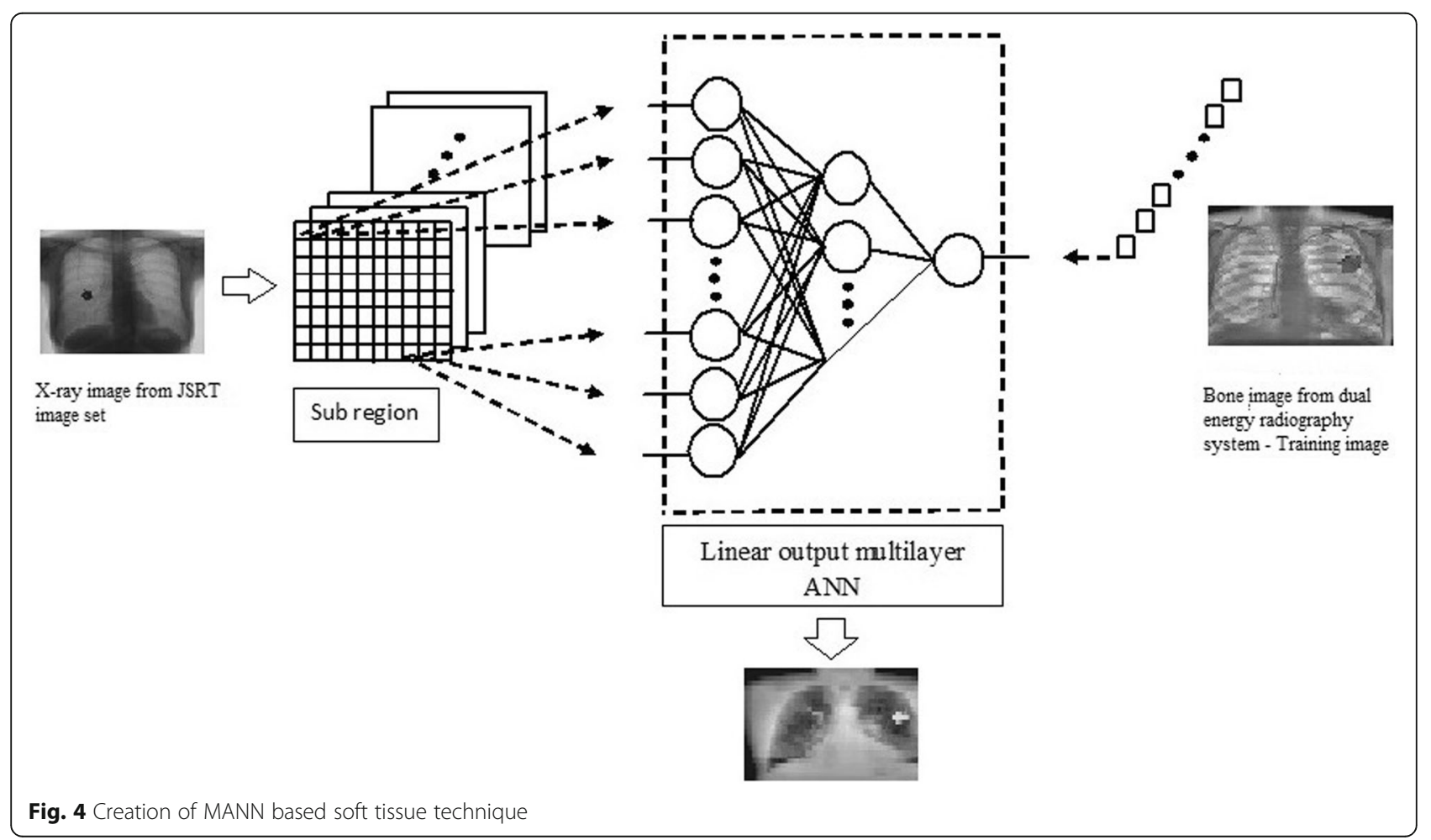


Table 4 Feature Extortion

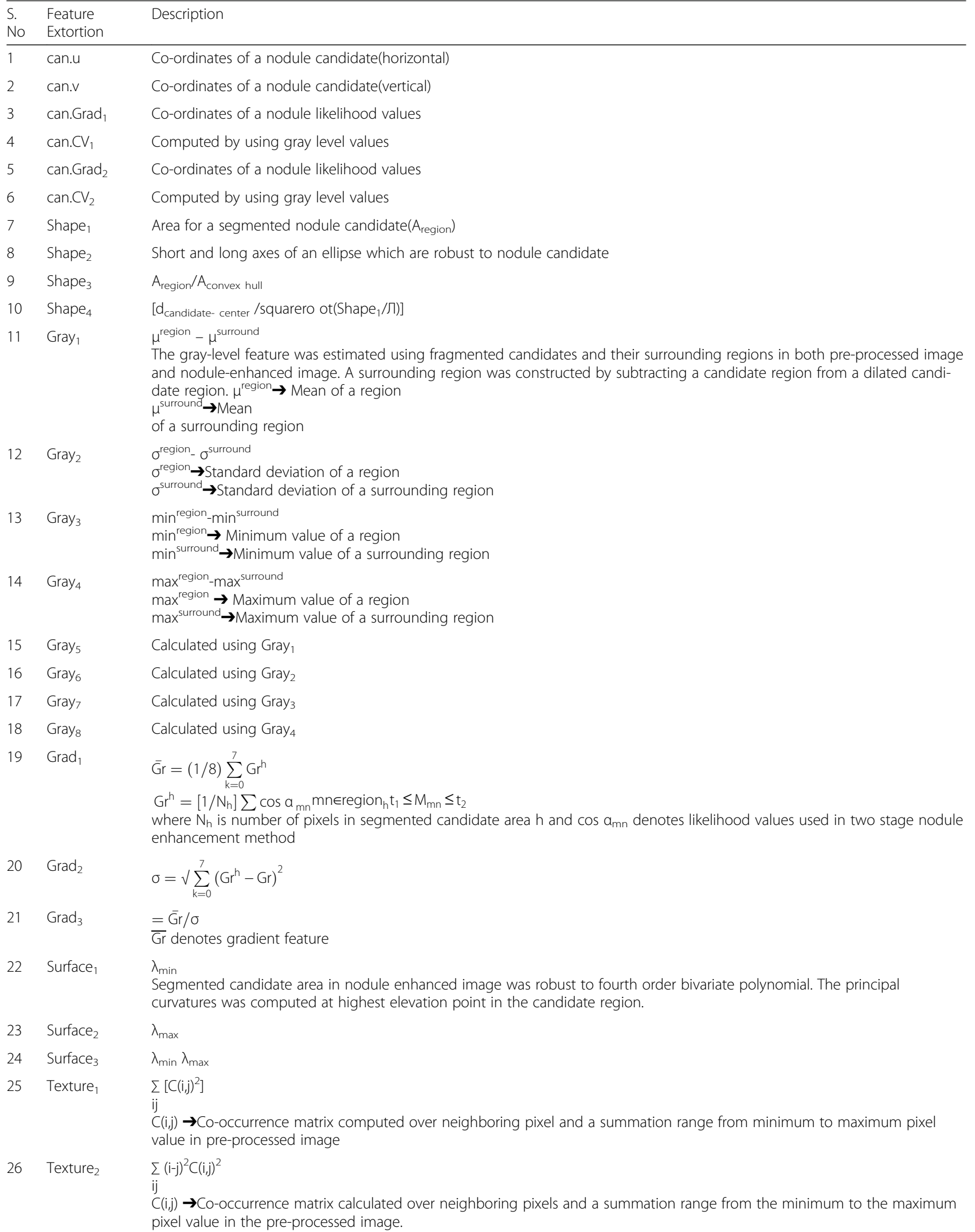


Table 4 Feature Extortion (Continued)

\begin{tabular}{|c|c|c|}
\hline $\begin{array}{l}\text { S. } \\
\text { No }\end{array}$ & $\begin{array}{l}\text { Feature } \\
\text { Extortion }\end{array}$ & Description \\
\hline 27 & Texture $_{3}$ & Calculated based on Texture ${ }_{1}$ and Texture $_{2}$ \\
\hline 28 & Texture $_{4}$ & Calculated based on Texture ${ }_{1}$ and Texture ${ }_{2}$ \\
\hline 29 & Texture $_{5}$ & Calculated based on Texture ${ }_{1}$ and Texture ${ }_{2}$ \\
\hline 30 & Texture $_{6}$ & Calculated based on Texture ${ }_{1}$ and Texture $_{2}$ \\
\hline 31 & False Positive & $\begin{array}{l}\text { Loverlap / Lregion Where Lregion is length of boundary of a candidate area and Loverlap is number of pixels on boundary } \\
\text { that overlap edge chain. }\end{array}$ \\
\hline
\end{tabular}

$$
\mathrm{D}_{\mathrm{H}}(\mathrm{u}, \mathrm{v})=\mathrm{G}_{\mathrm{H}}(\mathrm{u}, \mathrm{v})-\mathrm{S}
$$

This procedure was performed uninterruptedly in the lower resolution area. Thus, multi resolution area was crafted by using a multi resolution decomposition method. A vital asset of this method is as same as high resolution area $G_{H}(u, v)$ is acquired in eq. (8) is as follows:

$$
\mathrm{G}_{\mathrm{H}}(\mathrm{u}, \mathrm{v})=\mathrm{S}+\mathrm{D}_{\mathrm{H}}(\mathrm{u}, \mathrm{v})
$$

As a result, preference will be given to multi resolution region. After training of this technique, $x$-ray image produces bone area which was similar as training bone area. The bone area $f_{b}(u, v)$ was created from training neural network. Along with it, lung masking area $n(\mathrm{u}, \mathrm{v})$ and weighting parameter $\mathrm{w}_{\mathrm{c}}$ which was subtracted from the sub region $g(u, v)$ to create soft tissue in eq. (9).

$$
f(u, v)=g(u-i, v-j)-w_{c} x f_{b}(u, v) \times n(u, v)
$$

Where $f(u, v)$ denotes the soft tissue having different types of rib contrast using weighting parameter $\mathrm{w}_{\mathrm{c}}$.

To diminish rib-induced false positive and discern nodule overlapping ribs and clavicles, we have included MANN based on soft tissue technique within a proposed computer aided detection scheme.

Major issues faced during existing computer aided detection scheme was toward discerning nodule superimposed with ribs, rib crossings, and clavicles. During rib as well as clavicle suppression in $\mathrm{x}$-ray image, some nodule candidate has missed by soft tissue technique. We identified those nodule candidates which was done for non subtle nodule within $\mathrm{x}$-ray image through the following steps A) lung field extortion utilizing multidivision active shape model (M-ASM) [32] B) region of interest based on an abnormal identification by utilizing clustering watershed technique C) feature extortion D) classification. During this scenario, sensitivity of proposed computer aided detection scheme is lower than

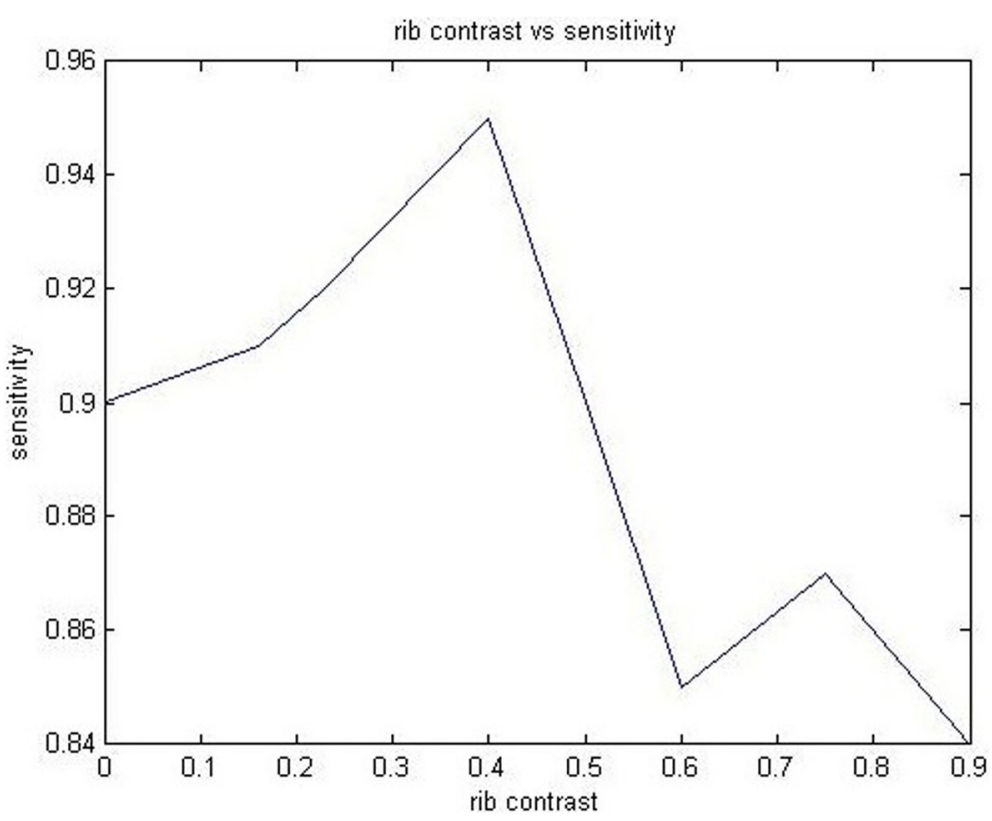

Fig. 5 Rib contrasts vs sensitivity 
the sensitivity of existing computer aided detection scheme for non subtle nodules.

However, sensitivity of existing computer aided detection scheme has progressed by minimum improvement.

\section{Proposed computer aided detection scheme}

Figure 4 demonstrates proposed computer aided detection scheme. It incorporates 4 steps: A) lung field extortion utilizing multi-division active shape model (M-ASM) B) region extortion based on an abnormal identification by utilizing clustering watershed method C) feature extortion D) an abnormal categorization utilizing support vector machine.

Lung field extortion utilizing multi-division active shape model (M-ASM) Multi-division active shape model (M-ASM) were permitted during lung field extortion [33] for structural boundary. It determines multiple segments [34] called heart, aorta as well as rib-cage. The node specified active shape model was discovered through each segment for a particular boundary which resulted in a marked improvement in boundary accuracy. After lung field extortion, background trend correction technique based on second order bivariate polynomial function was employed using eq. (10)

$$
\mathrm{F}(\mathrm{x}, \mathrm{y})=\mathrm{ax}^{2}+\mathrm{by}^{2}+\mathrm{cxy}+\mathrm{dx}+\mathrm{ey}+\mathrm{f}
$$

where $a, b, c, d, e, f$ are co-efficients and $F(x, y)$ denotes an image. In this, $x$ and $y$ indicate pixel coordinates.

Segmented lung field image applies different gray level morphological open operation $[35,36]$ forming nodule enhanced images and a nodule enhanced image have modified likelihood map. MANN based soft tissue technique [28] have created after lung field segmentation to suppress rib and clavicle in $\mathrm{x}$-ray image. In Fig. 3, a soft tissue image recognized nodule candidate by utilizing two step nodule enhancement technique (which was done for subtle nodules). Region of interest have identified using soft tissue and $x$-ray image and feature based on these images are effective. Some nodule had related bone feature, i.e., shape, size, contrast, orientation. However, these features were suppressed using this technique. Due to suppressed feature, identified nodule may be misinterpreted as non nodule in the soft tissue image. To identify such misinterpretation, same feature set may be extorted at the equivalent location in $\mathrm{x}$-ray image [37, 38].

\section{Region extortion based on an abnormal identification} by utilizing clustering watershed method Region of interest was identified based on an abnormality by utilizing clustering watershed technique after lung field segmentation. By utilizing a clustering watershed technique [39], the jagged abnormal area was segmented using multiple catchment basin [40, 41]. Every least point was enclosed by it; thus, there were one or more peaks, each of which was included by a cluster of associated pixels that comprised a catchment basin. From the multiple catchment basin, a single abnormal area was concluded by following clustering method: first, primary cluster was included abnormal location (as a point) decided by initial identification step. Next, clusters connected to primary cluster were inserted. Attached clusters were

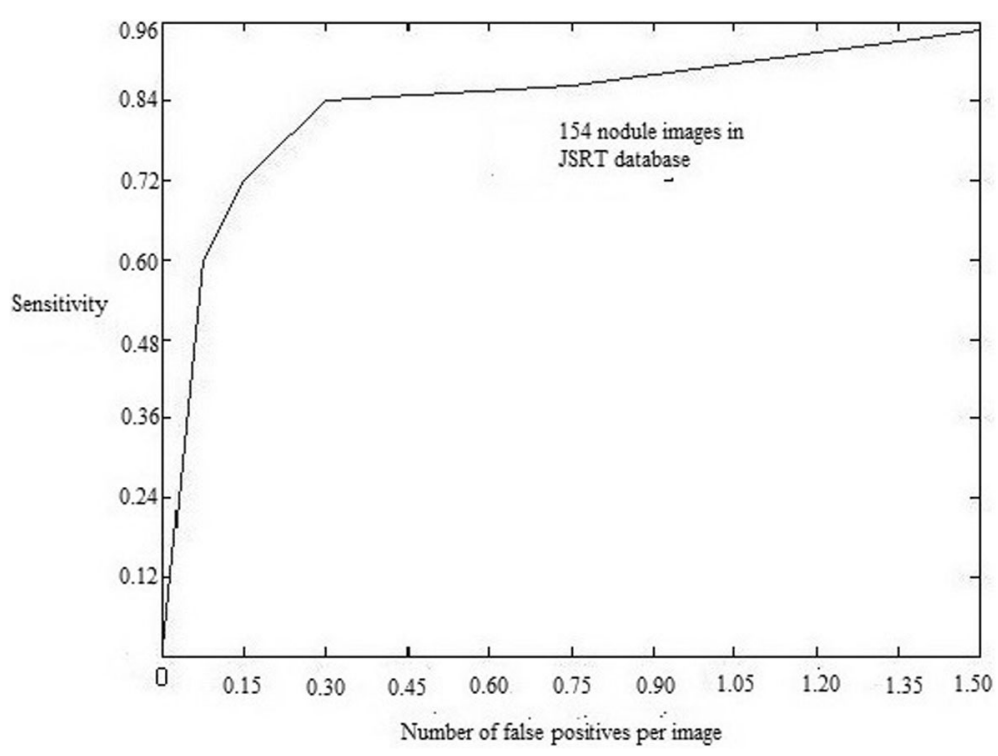

Fig. 6 Sensitivity vs number of false positive per image 
recognized through utilizing least value between peaks in primary cluster.

Feature extortion Sixty two morphological and graylevel-based features were extorted from the region of interest through $\mathrm{x}$-ray and soft tissue image. The features extorted from $x$-ray and soft tissue image using proposed computer aided detection scheme were listed in Table 4.

Classification After nodule [42] area extortion, feature extortion [43] have given as an attempt to non linear support vector machine [44] (SVM) for categorizing abnormality. Based on feature extortion, a common size of an abnormal area $(17.8 \mathrm{~mm})$ was detected. An SVM classifier [44] has trained/tested by applying cross-validation experiment and FROC analysis has attained $[45,46]$.

\section{Results}

Here, proposed computer aided detection scheme has been demonstrated. First, MANN based soft tissue technique was created. Next, the soft tissue image having different rib contrast was plotted using sensitivity in favor of finding peak value.

\section{MANN based soft tissue technique training}

Four images from JSRT database have used to train MANN. one was normal while other three were abnormal. ROC curve is shown in Figure 1. Massive artificial neural network size has $9 \times 9$ pixels.

It was enough to wrap rib width in the image. The limited figure of bone images was utilized in three layered, massive training artificial neural network to restrain rib where input, hidden and output units was 81, 20 and 1 respectively. Figure 5 demonstrates plotted rib contrast values using soft tissue images. It is explained in the next section.

\section{Nodule candidate identification}

We subtract bone image from the novel $x$-ray image as per eq. (10) in Section 2.3. From this, we obtain a soft tissue image. There was a factor Mc to regulate rib disparity in soft tissue images. A rib disparity [47] is a factor obtain from a different soft tissue image by the use of the weighting parameter(eq. (10)) and it's range lies between 0 and 1 . In Fig. 5, highest sensitivity value (95\%) is concluded while rib (contrast) parameter $M_{c}$ was 0.4 . As in soft tissue image, most nodules were identified in different rib contrast during a candidate identification step. In a plotted graph, $84 \%$ candidates have max code (nodule likelihood) values represent probability map were utilized toward an origin point. The nodule candidate identification in MANN based soft tissue technique utilizing JSRT image set was achieved 95\% (135/
140) sensitivity. In Fig. 6, Number of false positives per image vs Sensitivity were plotted. False positive of 1 were obtained by using $84 \%$ sensitivity for 154 nodule images. The values of features extracted from $x$-ray and soft tissue image using proposed computer aided detection scheme are shown in Table 5.

Table 6 indicates a sensitivity and false positive of several computer aided detection schemes which was utilized JSRT image set. Wei et al. [48] gave information about their CAD scheme which attained $80 \%$ sensitivity and 5.4 FPs per image by means of utilizing JSRT database. Due to large amounts of false positive (5.4), radiologist accuracy in identifying lung nodule was not

Table 5 Features values from $x$-ray and soft tissue image using proposed computer aided detection scheme

\begin{tabular}{|c|c|c|}
\hline Feature Extortion & Values in $x$-ray image & Values in soft tissue image \\
\hline can.u & 6 & 7 \\
\hline can.v & 7.5 & 8.5 \\
\hline can.Grad 1 & 4.5 & 5.5 \\
\hline can.CV 1 & 0.65 & 0.75 \\
\hline can.Grad 2 & 6.7 & 7.7 \\
\hline can.CV 2 & 7.2 & 8.2 \\
\hline Shape $_{1}$ & 7 & 8 \\
\hline Shape $_{2}$ & 6.6 & 7.6 \\
\hline $\mathrm{Shape}_{3}$ & 4.5 & 5.5 \\
\hline $\mathrm{Shape}_{4}$ & 5.8 & 6.8 \\
\hline Gray $_{1}$ & 7 & 8 \\
\hline $\mathrm{Gray}_{2}$ & 8.2 & 9.2 \\
\hline $\mathrm{Gray}_{3}$ & 8.4 & 9.4 \\
\hline $\mathrm{Gray}_{4}$ & 9.2 & 8.2 \\
\hline Gray $_{5}$ & 7 & 8 \\
\hline Gray $_{6}$ & 8.2 & 9.2 \\
\hline $\mathrm{Gray}_{7}$ & 8.4 & 9.4 \\
\hline Gray $_{8}$ & 9.2 & 9.2 \\
\hline $\mathrm{Grad}_{1}$ & 37 & 47 \\
\hline $\mathrm{Grad}_{2}$ & 30 & 40 \\
\hline $\mathrm{Grad}_{3}$ & 1.23 & 1.175 \\
\hline Surface $_{1}$ & 25 & 35 \\
\hline Surface $_{2}$ & 27 & 37 \\
\hline Surface $_{3}$ & 675 & 1295 \\
\hline Texture $_{1}$ & 30 & 40 \\
\hline Texture $_{2}$ & 32 & 42 \\
\hline Texture $_{3}$ & 34 & 44 \\
\hline Texture $_{4}$ & 36 & 46 \\
\hline Texture $_{5}$ & 38 & 48 \\
\hline Texture $_{6}$ & 40 & 50 \\
\hline False Positive & 2.5 & 1 \\
\hline
\end{tabular}


Table 6 Performance comparison of several existing computer aided detection systems which used JSRT Database

\begin{tabular}{|c|c|c|c|c|c|}
\hline Author & Sensitivity & FPs/image & Methodology & Classifier & Database \\
\hline Wei et al. [48] & $\begin{array}{l}80 \% \\
(123 / 154)\end{array}$ & $\begin{array}{l}5.4(1333 / 247) \text { (less } \\
\text { accuracy due to high } \\
\text { FPs) }\end{array}$ & Forward stepwise selection & $\begin{array}{l}\text { Fisher linear } \\
\text { discriminant }\end{array}$ & $\begin{array}{l}\text { All abnormal as well as } \\
\text { normal image inside } \\
\text { JSRT(247) }\end{array}$ \\
\hline Coppini et al. [49] & $\begin{array}{l}60 \%(93 / \\
154)\end{array}$ & $4.3(662 / 154)$ & Neural network filter & $\begin{array}{l}\text { Fisher linear } \\
\text { discriminant }\end{array}$ & $\begin{array}{l}\text { All nodule image in } \\
\text { JSRT(154) }\end{array}$ \\
\hline Schilham et al. [13] & $\begin{array}{l}51 \%(79 / \\
154) \\
67 \% \\
(103 / 154)\end{array}$ & $2(308 / 154) 4(616 / 154)$ & Image filtering Based on Regression & $\begin{array}{l}\text { Fisher linear } \\
\text { discriminant }\end{array}$ & $\begin{array}{l}\text { All nodule image in } \\
\text { JSRT(154) }\end{array}$ \\
\hline Hardie et al. [50] & $\begin{array}{l}80 \% \\
(112 / 140) \\
63 \%(88 / \\
140)\end{array}$ & $\begin{array}{l}5.0(700 / 140) \\
2(280 / 140)\end{array}$ & $\begin{array}{l}\text { Active shape model and new } \\
\text { weighted multi- scale conver gence- } \\
\text { index }\end{array}$ & $\begin{array}{l}\text { Fisher linear } \\
\text { discriminant }\end{array}$ & Nodule image in JSRT(140) \\
\hline Chen et al. [31] & $\begin{array}{l}71 \% \\
(100 / 140)\end{array}$ & $2(466 / 233)$ & $\begin{array}{l}\text { Computer aided detection using } \\
\text { neural filter }\end{array}$ & $\begin{array}{l}\text { Support } \\
\text { Vector } \\
\text { Machine } \\
\text { (SVM) }\end{array}$ & $\begin{array}{l}\text { Nodule and Normal image } \\
\text { in JSRT(233) }\end{array}$ \\
\hline $\begin{array}{l}\text { Proposed MANN based } \\
\text { soft tissue technique }\end{array}$ & $\begin{array}{l}72.85 \% \\
(102 / 140)\end{array}$ & $1(233 / 233)$ & MANN for rib suppression & $\begin{array}{l}\text { Support } \\
\text { Vector } \\
\text { Machine } \\
\text { (SVM) }\end{array}$ & $\begin{array}{l}\text { Nodule and normal image } \\
\text { in JSRT(233) }\end{array}$ \\
\hline
\end{tabular}

progressed. Hardie et al. gave information about their CAD schemes which was marked $63 \%$ nodules in JSRT image set and 2 FPs per image [50]. Their concert was considered by utilizing $25 \mathrm{~mm}$ distance decision for finding.

out true positive (TP) recognitions. Concert of our CAD system with MANN based soft tissue technique (72.85\%) has substantially higher than Chen reported scheme [31].

\section{Discussion}

By utilizing dual-energy subtraction [51, 52] technique, it was very complex task in the direction of gathering larger radiation dose. MANN based soft tissue technique has the possibility toward improving sensitivity with specificity which was buried as a consequence of suppressing rib with a discriminating nodule contained by an another regular anatomic structure. For an obscuring bone, single exposure based dual energy subtraction technique [44] had addressed. By utilizing this technique, the soft-tissue image was created. When we use this technique, sensitivity and specificity were improved. A fixed number of hospitals utilize radiography systems (www.ijetae.com, www.ajronline.org) [53, 54] by dualenergy subtraction, because dedicated tools for acquiring dual-energy X-ray exposures [55] was required.

As within $\mathrm{x}$-ray image, we observe nodule candidate during rib contrast [56] parameter variation. a false positive was noticed. In our approach, MANN based soft tissue technique was utilized in direction for building soft tissue image. It was trained using four $\mathrm{x}$-ray images (one was a normal image while other three was nodule image) from JSRT image set and corresponding bone images. Highest rib contrast factor has been observed. We utilize this trained MANN on behalf of restraining ribs and clavicles.

In a proposed CAD, MANN based soft tissue technique has integrated 2 diverse images (bone, $\mathrm{x}$-ray image) together and extorted feature set using soft tissue image after lung field segmentation. During this technique, a constant rib contrast factor was preferred which was represented as maximum peak in feature recognition in favor of every abnormal cases utilizing soft image for reducing false positives which are caused by ribs.

\section{Conclusion}

Here, the proposed computer aided detection (CAD) scheme using MANN based soft tissue technique is being widened as $72.85 \%$ sensitivity and $72.96 \%$ accuracy after sub region identification. Hence, the subtle nodule was detected using a nonlinear filter. In this work, the nonlinear filter was MANN. It is a promising method for radiologists to recognize an abnormality by $\mathrm{x}$-ray images from JSRT image set. By utilizing MANN filter, false positive of the proposed CAD scheme have diminished to 1 which was lower than previous works.

\section{Abbreviations \\ CAD: Computer aided diagnosis; MANN: Massive Artificial Neural Network; JSRT: Japanese society of radiological technology; FP: False Positive}

\section{Acknowledgements}

We will give our sincere thanks to Kamaraj College of Engineering and Technology, Virudhunagar, India for doing this research work in the Department of Electronics and Communication Engineering. Our special thanks to Dr. Anant Achary, M.Tech., Ph.D., Principal, Kamaraj college of 
Engineering and Technology, Virudhunagar, India for his encouragement and continuous support for this research work. Our regards to Dr. Joe Pradeep Kumar, MBBS, Indian MRI Diagnostic \& Research Limited, Madurai for his guidance and validation of data. The authors would like to thank all anonymous reviewers for their advice.

\section{Authors' contributions}

Mr.R.Kishore and Dr.R.Suresh Babu wrote the manuscript. Both of them provided critical revisions. All authors read and approved the final manuscript.

\section{Funding}

no funding received.

\section{Availability of data and materials}

The dataset that support the findings and conclusion of this study are publicly available.

\section{Ethics approval and consent to participate}

Not Applicable.

\section{Consent for publication}

Not Applicable.

\section{Competing interests}

The authors have declared that there is no competing interest.

Received: 16 April 2020 Accepted: 13 August 2020

Published online: 31 October 2020

\section{References}

1. Okuhara T, Ishikawa H, Urakubo A, Hayakawa M, Yamaki C, Takayama T, Kiuchi T. Cancer information needs according to cancer type: A content analysis of data from Japan's largest cancer information website. Prev Med Rep. 2018;12:248-52.

2. Brian Tzung PJ, Julien MD. "Lung Cancer Screening", Medical Management of the Thoracic Surgery. Patient. 2010:197-200.

3. American Cancer Society. American Cancer Society Complete Guide to Complementary and Alternative Cancer Therapies. 2nd ed. Atlanta: American Cancer Society; 2002

4. Office for National Statistics, Cancer survival by stage at diagnosis for England, 2019

5. Henschke Cl, McCauley DI, Yankelevitz DF, Naidieh DP, McGuinness G, Miettinen OS, Libby DM, Pasmantier MW, Koizumi J, Altorki NK, Smith JP. Early lung cancer action project: Overall design and findings from baseline screening. Lancet. 1999;354:99-105.

6. Austin JH, Romney BM, Goldsmith LS. Missed bronchogenic carcinoma: Radiographic findings in 27 patients with a potentially resectable leison evident in reterospect. Radiology. 1992;182:115-22

7. Shah PK, Austin JH, White CS, Patel P, Haramati LB, Pearson GD, Shiau MC, Berkmen YM. Missed non- small cell lung cancer: Radiographic findings of potentially resectable lesions evident only in retrospect. Radiology. 2003; 226:235-41.

8. Lin JS, Lo SB, Hasegawa A, Freedman MT, Mun SK. Reduction of false positives in lung nodule detection using a two-level neural classification. IEEE Trans Med Imaging. 1996;15:206-16.

9. Ballard S. A Ladder Structured Decision Tree for Recognizing Tumors in Chest Radiographs. IEEE Trans Comput. 1976;C-25(5):503-13.

10. Cox GS, Hoare FJ, de Jager G. Experiments in lung cancer nodule detection using texture analysis and neural network classifiers, Third South African Workshop on Pattern Recognition; 1992.

11. Le K. Automated detection of early lung cancer and tuberculosis based on X-ray image analysis. In: Proc. WSEAS International Conference on Signal, Speech and Image Processing; 2006. p. 1-6.

12. Campadelli P, Casiraghi E, Artioli D. A fully automated method for lung nodule detection from postero-anterior chest radiographs. IEEE Trans Med Imaging. 2006:25(12):1588-602.

13. Schilham AMR, Ginneken BV, Loog M. A computer-aided diagnosis system for detection of lung nodules in chest radiographs with an evaluation on a public database. Med Image Anal. 2006;10(2):247-58.
14. Park M, Jin JS, Wilson LS. Detection of abnormal texture in chest X-rays with reduction of ribs. In: Proc. Pan-Sydney area workshop on visual information processing; 2004.

15. Zhang $L$, Gao X. Research on translation invariant wavelet transform for classification in mammograms. In: Proc. 3rd international conference on natural computation; 2007.

16. Lo SB, Lou SL, Lin JS, Freedman MT, Mun SK. Artificial convolution neural network techniques and applications for lung nodule detection. IEEE Trans Med Imaging. 1995;14:711-8.

17. Hayashibe R, Asano N, Hirohata H, Okumura K, Kondo S, Handa S, Takizawa M, Sone S, Oshita S. An automatic lung cancer detection from X-ray images obtained through yearly serial mass survey. In: Proc. International conference on image processing; 1996. p. 343-6.

18. Matsumoto T, Doi K, Kano A, Nakamura H, Nakanishi T. Evaluation of the potential benefit of computer aided diagnosis (CAD) for lung cancer screenings using photofluorography: analysis of an observer study. Nihon Igaku Hoshasen Gakkai Zasshi. 1993;53:1195-207.

19. Li F, Engelmann R, Doi K, MacMahon H. Improved detection of small lung cancers with dual-energy subtraction chest radiography. AJR Amer J Roentgenol. 2008;190:886-91.

20. Ide K, Mogami H, Murakami T, Yasuhara Y, Mochizuki T. Detection of lung cancer using single-exposure dual-energy subtraction chest radiography. Radiat Med. 2007;25:195.

21. Manji F, Wang J, Norman G, Wang Z, Koff D. Comparison of dual energy subtraction chest radiography and traditional chest $\mathrm{X}$-rays in the detection of pulmonary nodules. Quant Imaging Med Surg. 2016;6(1):1-5. https://doi. org/10.3978/j.issn.2223-4292.2015.10.09.

22. Bo Zhou, Xunyu Lin, Brendan Eck, Jun Hou, David Wilson, "Generation of virtual dual energy images from standard single-shot radiographs using multi-scale and conditional adversarial network", Robotics Institute, School of Computer Science, Carnegie Mellon University, Department of Biomedical Engineering, Case Western Reserve University,2018, arXiv:1810.09354.

23. Suzuki K. Pixel-Based Machine Learning in Medical Imaging. Int J Biomed Imaging. 2012;2012:1-18.

24. Kobayashi T, Xu X-W, MacMahon H, Metz CE, Doi K. Effect of a Computeraided Diagnosis Scheme on Radiologists Performance in Detection of Lung Nodules on Radiographs. Radiology. 1996;199(3):843-8.

25. Lee D, Kim H, Choi B, Kim H-J. Development of a deep neural network for generating synthetic dual-energy chest $\mathrm{X}$-ray images with single $\mathrm{X}$-ray exposure. Res Inst Health Sci Phys Med Biol. 2018:1-23.

26. Shiraishi J, Li Q, Suzuki K, Engelmann R, Doi K. Computer aided diagnostic scheme for detection of lung nodules on chest radiographs: Localized search method based on anatomical classification. Med Phys. 2006;33(7):2642-53.

27. Udeshani KAG, Meegama RGN, Fernando TGI. Statistical Feature-based Neural Network Approach for the Detection of Lung Cancer in Chest X-Ray Images. Int J Image Proc. 2011;5:425-34

28. Suzuki $K$, Abe $H$, MacMahon $H$, Doi K. Image processing technique for suppressing ribs in chest radiographs by means of massive training artificial neural network. IEEE Trans Med Imaging. 2006;25(4):406-16.

29. Ture H, Kayikcioglu T. Detection and Segmentation of Nodules in Chest Radiographs Based on Lifetime Approach: (c) Springer; 2017.

30. Chen S, Suzuki K. Computerized detection of lung nodules by Means of 'virtual dual energy' Radiography. IEEE Trans Biomed Eng. 2013;60(2):369-78.

31. Chen S, Suzuki K, Mac Mahon H. Development and evaluation of a computer-aided diagnostic scheme for lung nodule detection in chest radiographs by means of two-stage nodule enhancement with support vector classification. Med Phys. 2011;38(4):1844-58.

32. Paola Campadelli, Elena Casiraghi, Simon Columbano, "Lung segmentation and nodule detection in postero anterior chest radiographs", pp 1 -8.

33. van Ginneken B, Frangi AF, Staal JJ, Romeny B Mt H, Viergever MA. Active shape model segmentation with optimal features. IEEE Trans Med Imaging. 2002:21(8):924-33.

34. Jiahui Wang JT, Dobbins III, Li Q. Automated lung segmentation in digital chest tomosynthesis. Med Phys. 2012;39:732-41.

35. Serra J. Image analysis and Mathematical Morphology, vol. 1. New York: Academic; 1982

36. Haralickv RM, Sternberg SR, Zhuang X. Image analysis using mathematical morphology. IEEE Trans Pattern Anal Mach Intell. 1987:532-50.

37. Li C, et al. False-Positive Reduction on Lung Nodules Detection in Chest Radiographs by Ensemble of Convolutional Neural Networks. IEEE Access. 2018;6:16060-7 
38. Orban $\mathrm{G}$, Horvath $\mathrm{G}$. Algorithm fusion to improve detection of lung cancer on chest radiographs. Int J Intell Comput Cybern. 2012.

39. Vincent L, Soille P. Watersheds in Digital Spaces: An efficient algorithm based on immersion simulations. IEEE Trans Pattern Anal Mach Intell. 1991; 13(6):583-98.

40. Kiroğlu. Comparison of segmentation algorithms for detection of hotspots in bone scintigraphy images and effects on CAD systems. Biomed Res. 2017:28(2):676-83.

41. Raghava NS, Kumar GS. Image Processing for Synthesizing Lung Nodules: A Experimental Study. J Appl Sci. 2006;6:1238-42.

42. Iqbal S, labal K, Arif F, Shaukat A, Khanum A. Potential Lung Nodules Identification for Characterization by Variable Multistep Threshold and Shape Indices from CT Images. Comput Math Methods Med. 2014; Hindawi Publishing Corporation.

43. Boroczky L, Zhao L, Lee KP. Feature subset selection for improving the performance of false positive reduction in lung nodule CAD. IEEE Symp Comput Based Med Syst. 2005;10:504-11.

44. Egan JP, Greenberg GZ, Schulman Al. Operating characteristics, signal detectability, and the method of free response. J Acoust Soc Amer. 1961;33: 993-1007.

45. Qin C, Yao D, Shi Y, Song Z. Computer-aided detection in chest radiography based on artificial intelligence: a survey. Biomed Eng. 2018;17(1).

46. Senthil Kumar TK, Ganesh EN, Umamaheswari R. Lung nodule volume growth analysis and visualization through auto-cluster k-means segmentation and centroid/shape variance based false nodule elimination. Biomed Res. 2017:28(5).

47. Suzuki K. Machine Learning in Medical Imaging Before and After Introduction of Deep Learning. J Med Imaging Inf Sci. 2017;34(2):14-24.

48. Wei J, Hagihara Y, Shimizu A, Kobatake H. Optimal image feature set for detecting lung nodules on chest X-ray images. In: Proc. Computer Assisted Radiology Surgery; 2002. p. 706-11.

49. Coppini G, Diciotti S, Falchini M, Villari N, Valli G. Neural networks for computer-aided diagnosis: Detection of lung nodules in chest radiograms. IEEE Trans Inf Technol Biomed. 2003;7(4):344-57.

50. Hardie RC, Rogers SK, Wilson T, Rogers A. Performance analysis of a new computer aided detection system for identifying lung nodules on chest radiographs. Med Image Anal. 2008:12:240-58.

51. Kuhlman JE, Collins J, Brooks GN, Yandow DR, Broderick LS. Dual-Energy Subtraction Chest Radiography: What to Look for beyond Calcified Nodules. Radiographics. 2006;26:79-92.

52. Novak NJ. Does BMI Affect Diagnostic Efficacy of Computer Aided Diagnostic Software in the Identification of Malignant Pulmonary Nodules in Dual Energy Subtracted Chest Radiographs. A publication of case western reserve university. 2015;11(2):1-2.

53. Suzuki K. Computational Intelligence in Biomedical Imaging; 2014

54. Jawahar CV, Li H, Mori G, Schindler K. Computer Vision - ACCV 2018: Springer Science and Business Media LLC; 2019.

55. Shu T, Zhang B, Yan Tang Y. An extensive analysis of various texture feature extractors to detect Diabetes Mellitus using facial specific regions. Comput Biol Med. 2017.

56. Song I, Jeong Geun Y, Park JH, Lee KMS, Chung MJ. Color radiography in lung nodule detection and characterization: comparison with conventional gray scale radiography. BMC Med Imaging. 2016;16:1-7.

\section{Publisher's Note}

Springer Nature remains neutral with regard to jurisdictional claims in published maps and institutional affiliations.

Ready to submit your research? Choose BMC and benefit from:

- fast, convenient online submission

- thorough peer review by experienced researchers in your field

- rapid publication on acceptance

- support for research data, including large and complex data types

- gold Open Access which fosters wider collaboration and increased citations

- maximum visibility for your research: over $100 \mathrm{M}$ website views per year

At BMC, research is always in progress.

Learn more biomedcentral.com/submissions 